\title{
Medical Students Perception to Different Types of Reasoning Questions in Histology Lectures
}

\author{
Suresh Narayanan, ${ }^{1}$ Nachiket Shankar, ${ }^{2}$ Vimala Ananthy ${ }^{3}$ \\ 'Department of Anatomy, Sri Manakula Vinayagar Medical College and Hospital, Puducherry, India \\ 2Department of Anatomy, St. John's Medical College and Hospital, Bangalore, Karnataka, India \\ ${ }^{3}$ Department of Pharmacology, Mahatma Gandhi Medical College and Research Institute, Puducherry, India
}

Disclose and conflicts of interest: none to be declared by all authors

\begin{abstract}
Introduction: An effective questioning strategy can promote learner engagement during histology lectures for undergraduate medical students. The objective of the current study was to assess student perceptions about structurebased and function-based reasoning questions during histology lectures among first-year medical undergraduates. Methods: This was a cross-sectional analytical study conducted among 150 students. Reasoning questions were formulated for seven general histology lectures. The students were exposed to two or three structure-based and function-based reasoning questions during the lecture. The students were given around two minutes to discuss the answers prior to discussion by the teacher. The questions were revisited at the end of the sessions to reinforce the underlying concepts. The students completed an anonymous perception questionnaire that consisted of 10 items and two open-ended questions on the merits and limitations of the intervention. The Wilcoxon signed-rank test and the Mann-Whitney $U$ test were used to estimate group differences. Results: The perceptions of students about both structure and function-based reasoning questions were positive. The perceptions about three items were significantly higher for the function-based reasoning questions. Significant gender differences in the perceptions about both types of questions were also noted for three items. Merits of the question-based lectures included a better understanding and increased interest levels. Inadequate coverage of the topic during lectures was a perceived demerit. Conclusions: Both structure-based and function-based reasoning questions incorporated in histology classes improved learner engagement. Further research could focus on the change in learning outcomes associated with the reasoning approach described in the present study.

Keywords: Questions; Reasoning; Histology; Lectures; Perceptions; India.
\end{abstract}

\section{Introduction}

Histology represents the foundation for proper comprehension of normal physiological and pathological processes of diseases. ${ }^{1}$ In our institution, histology teaching is still based on lectures and educators often find it difficult to promote student participation during lectures. Learners often try to memorize the structural organization of tissues like staining characteristics, the pattern of arrangement of structures and the shape and position of nuclei, but fail to explore the underlying rationale behind these characteristics. ${ }^{1}$ In pedagogical approaches like live digital imaging and draw-along techniques, there is a behavioral engagement with the learner through realtime illustration of microscopic slides and creation of diagrams. ${ }^{2-4}$ But these teaching methods do not take into consideration whether the learner has understood the reasoning behind the arrangement of the structural components. Medical educators often correlate histological features with physiological concepts for better correlation of its functions. ${ }^{5}$ But the real-world applications of histology are seldom addressed in lectures. Hence, it is imperative to design a teaching strategy for histology lectures that incorporates these elements.

Student engagement refers to a wide range of activities that enhance learning and professional development in students. ${ }^{6}$ It is often viewed as being multidimensional and involves aspects of students' emotions, behavior and cognition..$^{6,7}$ Many factors like motivation, academic integration and emotional connect have been linked to student engagement.6,7 Previous studies on histology have focused on active draw-along techniques and concept mapping to engage the learner. ${ }^{3,4}$ Since student engagement leads to higher order thinking and better learning outcomes, it is vital to understand what engages the millennial learners in a lecture setting.

Questions stimulate learning by activating appropriate cognitive processes and can thus be used to advantage in lectures. ${ }^{8}$ There are many ways of classifying questions. ${ }^{9,10}$ Questions may either be convergent or divergent. Convergent questions are close-ended and usually have few options or a single correct answer. Divergent questions are openended and require higher order thinking skills to 
answer them. They require the construction and elaboration of an answer which could encompass different viewpoints rather than be restricted to one or a few best answers. ${ }^{9}$ Bloom's taxonomy of cognitive levels and knowledge dimensions may also be used to classify questions. ${ }^{10}$ Question circles provide a useful conceptual framework for the formulation and utilization of questions in the classroom. ${ }^{10}$ The three circles relate to factual content, personal experiences and contexts. It has been suggested that questions be initially related to a single circle. Later the level of complexity could be increased to include two circles, finally leading to questions that require all three aspects to be integrated in order to answer them. ${ }^{10}$ An effective questioning strategy stimulates rationale thinking, promotes learner engagement, encourages reflection, and aids in the construction of new knowledge. ${ }^{11}$ Even experienced educators often rely on recall-based questions that fail to stimulate deeper thinking. However, asking novice learners unrealistically difficult questions can lead them to lose their confidence and result in disengagement with learning. 11,12

Even though previous studies have highlighted the effectiveness of questioning techniques in facilitating thought processes ${ }^{11,12}$, there is no empirical evidence about the association between of the type of question asked and learner engagement. In the present study, two types of reasoning questions, namely, structurebased (rationale behind the structural arrangement) and function-based (functional relevance associated with a familiar real-world scenario) were introduced during general histology lectures. These interventions were attempted to increase learner engagement during these lectures. This strategy is in alignment with the teaching paradigm advocating a more interactive approach with an emphasis on knowledge synthesis. ${ }^{13}$ Since the students' perceptions about the learning environment are vital in determining learning outcomes ${ }_{1}^{14}$ understanding the role of question design in promoting student engagement could prove useful for academicians. The objective of the current study was to assess and compare student perceptions about structure-based and function-based reasoning questions during histology lectures among first-year medical undergraduates.

\section{Materials and Methods}

This was a cross-sectional analytical study which was approved by the institutional research and ethics committee (EC/29/2019). The entire cohort of 150 first year medical undergraduate students was introduced to reasoning questions in histology lectures. General histology lectures were chosen for the study because the students had some amount of background knowledge of this content from their higher secondary education. Additionally, these topics required a deeper conceptual understanding. A total of seven general histology lectures (one lecture per week) were taken by the same lecturer. The topics included epithelial glands, connective tissue, cartilage, bone, muscle, blood vessels and skin. The primary author formulated the reasoning questions for each session as well as clues to direct the learner to the response. Two senior faculty members checked the questions for their alignment with the objectives of the session, their mode of delivery, whether they promoted structural or functional reasoning and the appropriateness of the clues. After the objectives of the lecture were stated, the students were exposed to two or three reasoning questions during the lecture. It was ensured that a minimum of one structure-based and one functionbased reasoning question was incorporated into each lecture.

The following were examples of structurebased reasoning questions that were discussed during the lectures: 1) Why is the hyaline cartilage matrix homogenous in appearance?; 2) Why are the chondrocytes seen in isogenous groups?; 3) Why are serous acini darkly stained and mucus acinus pale stained?; 4) Why is there a difference in position and shape of nuclei between serous and mucous acini?; 5) Why do skeletal muscle fibres have multiple, flat and peripherally placed nuclei?; 6) Why is the internal elastic lamina prominently seen in a medium-sized artery? These questions were designed to explore the rationale behind the structural arrangement of tissues.

A few examples of function-based reasoning questions discussed were as follows: 1) Why do you develop sneezing and running nose while cleaning a dusty room?; 2) Why do you think your skin color is different from your classmates?; 3) Why do you have an oily face by the end of the day?; 4) Why is there a change in the blood pressure with increasing age?; 5) Why is there poor wound healing in an individual with diabetic ulcer; 6) What is the mechanism behind the muscle hypertrophy seen amongst bodybuilders? All the function-based reasoning questions explored the functional correlates of familiar real-world scenarios.

The students were given around two minutes to discuss the answers to each question with their peers using a "pair and share" technique. The answers from the students were discussed and reflected upon. If the students could not initially come up with answers, the lecturer provided clues to direct the learner, instead of providing the answers himself. For example, in the lecture on cartilage, the reasoning question posed was "Why is hyaline cartilage homogenous in appearance?". While the students were aware that cartilage is composed of cells, fibers, and ground substance, they were unable to explain the homogenous appearance. An image of Liu Bolin - The Invisible Man was used as a clue and the lecturer asked, "Why was it difficult to identify the invisible man?". This directed the learner towards the role of the refractive index in this context. At the end of each lecture, the reasoning questions 
were again revisited to reinforce the underlying concepts.

The students were asked to fill an anonymous perception questionnaire that consisted of 10 positively framed items which were required to be rated using a five-point Likert scale. A higher score indicated a more positive response. These items were related to students interest, level of understanding, preference over fact-based questions, time allotment for the discussions, motivation to take part in the discussions, stimulus to provoke a logical response, usefulness of the clues during the questioning session, ability to answer the question correctly at the end of the lecture, perceived improvement in their academic performance and recommendation of similar teaching methods in the future. The students' perception questionnaire was tested for internal consistency in a group of 14 students (Cronbach's alpha $=0.720$ ). The questionnaire also had two open-ended questions on the merits and limitations of the intervention. The questionnaire was administered to the students after the university examinations for ethical considerations. The difference in student perception score between structure and function-based reasoning questions was estimated using the Wilcoxon signed-rank test. The Mann-Whitney $U$ test was used to estimate gender differences in perception score. The statistical analysis was done using SPSS version 17.0 and a p-value less than 0.05 was considered statistically significant.

\section{Results}

A total of 126 students (52 male and 74 female) completed the perception questionnaire. The student perception scores for the structure and function-based reasoning questions are shown in Table 1 . It is evident from the table that for both types of questions, seven out of 10 items received a mean score of greater than four indicating a positive perception. However, for both types of questions, the time available for discussions, the usefulness of the clues and the ability to answer the questions by the end of the class were given a lower rating. Function-based reasoning questions were rated significantly higher on generating interest, enabling understanding and recommendation for future classes than the structure-based questions.

Table 1. Student's perceptions about structure and function-based questioning during histology lectures

\begin{tabular}{|c|c|c|c|c|}
\hline Sl. No. a & Statement in questionnaire & $\begin{array}{l}\text { Structural } \\
\text { reasoning } \\
\text { Mean } \pm \text { SDb } \\
\text { Median } \\
\text { (Interquartile } \\
\text { range) }\end{array}$ & $\begin{array}{l}\text { Functional } \\
\text { reasoning } \\
\text { Mean } \pm \text { SDb } \\
\text { Median } \\
\text { (Interquartile } \\
\text { range) }\end{array}$ & $\begin{array}{c}\text { P value } \\
\text { (Wilcoxon } \\
\text { signed rank } \\
\text { test) }\end{array}$ \\
\hline 1. & $\begin{array}{l}\text { The reasoning-based questions asked in the lectures were } \\
\text { interesting }\end{array}$ & $\begin{array}{l}4.12 \pm 0.71 \\
4(1)\end{array}$ & $\begin{array}{c}4.45 \pm 0.67 \\
5(1)\end{array}$ & $<0.001^{*}$ \\
\hline 2. & $\begin{array}{l}\text { I understood what the lecturer was trying to ask through his } \\
\text { questions }\end{array}$ & $\begin{array}{l}4.10 \pm 0.64 \\
4(1)\end{array}$ & $\begin{array}{l}4.11 \pm 0.67 \\
4(1)\end{array}$ & 0.892 \\
\hline 3. & $\begin{array}{l}\text { The reasoning questions enabled better understanding of } \\
\text { histology than lectures with fact-based questions }\end{array}$ & $\begin{array}{c}4.05 \pm 0.79 \\
4(1)\end{array}$ & $\begin{array}{c}4.20 \pm 0.78 \\
4(1)\end{array}$ & $0.033^{*}$ \\
\hline 4. & $\begin{array}{l}\text { The time given for discussing the reasoning questions was } \\
\text { adequate }\end{array}$ & $\begin{array}{c}3.78 \pm 0.71 \\
\quad 4(1)\end{array}$ & $\begin{array}{l}3.70 \pm 0.82 \\
\quad 4(1)\end{array}$ & 0.137 \\
\hline 5. & $\begin{array}{l}\text { The reasoning questions motivated me to take part in } \\
\text { discussions during the lecture }\end{array}$ & $\begin{array}{c}4.24 \pm 0.73 \\
4(1)\end{array}$ & $\begin{array}{c}4.35 \pm 0.71 \\
4(1)\end{array}$ & 0.073 \\
\hline 6. & $\begin{array}{l}\text { The reasoning questions stimulated me to think for logical } \\
\text { responses }\end{array}$ & $\begin{array}{l}4.12 \pm 0.74 \\
4(1)\end{array}$ & $\begin{array}{l}4.13 \pm 0.84 \\
4(1)\end{array}$ & 0.782 \\
\hline 7. & The clues given during the questioning session were useful & $\begin{array}{c}3.87 \pm 0.82 \\
4(1)\end{array}$ & $\begin{array}{c}3.82 \pm 0.86 \\
4(1)\end{array}$ & 0.470 \\
\hline 8. & $\begin{array}{l}\text { At the end of the lecture, I could correctly answer the } \\
\text { reasoning questions put forth during the lecture }\end{array}$ & $\begin{array}{c}3.78 \pm 0.82 \\
4(1)\end{array}$ & $\begin{array}{c}3.87 \pm 0.81 \\
4(1)\end{array}$ & 0.301 \\
\hline 9. & $\begin{array}{l}\text { The reasoning questions improved my academic performance } \\
\text { in histology }\end{array}$ & $\begin{array}{l}4.24 \pm 0.74 \\
4(1)\end{array}$ & $\begin{array}{l}4.19 \pm 0.82 \\
4(1)\end{array}$ & 0.332 \\
\hline 10. & $\begin{array}{l}\text { I would like to have similar methods of teaching in future } \\
\text { classes }\end{array}$ & $\begin{array}{c}4.35 \pm 0.65 \\
4(1)\end{array}$ & $\begin{array}{c}4.49 \pm 0.60 \\
5(1)\end{array}$ & $<0.001^{*}$ \\
\hline
\end{tabular}

aSI. No. - serial number; bSD - standard deviation; * - significant differences 
Male students gave significantly higher ratings than female students about their perceived understanding of both structure-based and function-based reasoning questions. Male students were also significantly more confident at being able to answer the function-based questions by the end of the class. Female students on the other hand felt that the clues provided by the teacher were significantly more useful for both types of questions as compared to male students. Female students were also significantly more satisfied with the time allotted for discussions of the structurebased questions (Tables 2 and 3).

Some of the responses to the open-ended questions were non-specific and therefore not included in the thematic analysis. Merits of the question-based lectures included a better understanding of how tissues appear the way they do, a more enjoyable learning experience compared to traditional lectures and a better appreciation of histological structures during laboratory sessions. A demerit that was expressed was the perceived inadequate coverage of the topic during lectures due to the time devoted to the discussion of the reasoning questions.

\section{Discussion}

In the present study, the authors attempted to increase student engagement during histology lectures by incorporating structure and function-based reasoning questions into the instructional design. This intervention was carried out to overcome the tendency for students to memorize features of histology slides without understanding the underlying structural or functional basis for these features. Student perceptions were assessed using a questionnaire having both qualitative and quantitative components. The perceptions of students about both structure and function-based reasoning questions were positive. However, significant differences were noted between the perceptions about structure-based and functionbased reasoning questions for a few parameters. Significant gender differences in the perceptions to both types of questions were also noted.

Even though the utility of questioning in enhancing learning has been well documented, the time allotted for questioning in teaching and learning sessions is often negligible. ${ }^{9,15}$ In the present study, specific questions were deliberately incorporated into the instructional

Table 2. Gender differences in student's perceptions about structure-based questioning during histology lectures

\begin{tabular}{|c|c|c|c|c|}
\hline Sl. No.a & Statement in questionnaire & $\begin{array}{c}\text { Male } \\
\text { Mean } \pm \text { SDb } \\
\text { Median } \\
\text { (Interquartile } \\
\text { range) }\end{array}$ & $\begin{array}{c}\text { Female } \\
\text { Mean } \pm \text { SDb } \\
\text { Median } \\
\text { (Interquartile } \\
\text { range) }\end{array}$ & $\begin{array}{c}\text { P value } \\
\text { (Mann- } \\
\text { Whitney U } \\
\text { test) }\end{array}$ \\
\hline 1. & $\begin{array}{l}\text { The reasoning-based questions asked in the lectures were } \\
\text { interesting }\end{array}$ & $\begin{array}{c}4.17 \pm 0.68 \\
4(1)\end{array}$ & $\begin{array}{l}4.08 \pm 0.73 \\
4(1)\end{array}$ & 0.452 \\
\hline 2. & $\begin{array}{l}\text { I understood what the lecturer was trying to ask through his } \\
\text { questions }\end{array}$ & $\begin{array}{l}4.32 \pm 0.51 \\
4(1)\end{array}$ & $\begin{array}{c}3.94 \pm 0.68 \\
4(0)\end{array}$ & $0.001^{*}$ \\
\hline 3. & $\begin{array}{l}\text { The reasoning questions enabled better understanding of } \\
\text { histology than lectures with fact-based questions }\end{array}$ & $\begin{array}{c}4.09 \pm 0.80 \\
4(1)\end{array}$ & $\begin{array}{l}4.02 \pm 0.79 \\
\quad 4(1.25)\end{array}$ & 0.579 \\
\hline 4. & $\begin{array}{l}\text { The time given for discussing the reasoning questions was } \\
\text { adequate }\end{array}$ & $\begin{array}{c}3.57 \pm 0.69 \\
4(1)\end{array}$ & $\begin{array}{l}3.93 \pm 0.69 \\
4(0.25)\end{array}$ & $0.005^{*}$ \\
\hline 5. & $\begin{array}{l}\text { The reasoning questions motivated me to take part in } \\
\text { discussions during the lecture }\end{array}$ & $\begin{array}{c}4.38 \pm 0.66 \\
4(1)\end{array}$ & $\begin{array}{c}4.13 \pm 0.76 \\
4(1)\end{array}$ & 0.072 \\
\hline 6. & $\begin{array}{l}\text { The reasoning questions stimulated me to think for logical } \\
\text { responses }\end{array}$ & $\begin{array}{l}4.06 \pm 0.80 \\
4(1)\end{array}$ & $\begin{array}{l}4.16 \pm 0.70 \\
4(1)\end{array}$ & 0.616 \\
\hline 7. & The clues given during the questioning session were useful & $\begin{array}{c}3.56 \pm 0.89 \\
4(1)\end{array}$ & $\begin{array}{c}4.09 \pm 0.68 \\
4(1)\end{array}$ & $0.001^{*}$ \\
\hline 8. & $\begin{array}{l}\text { At the end of the lecture, I could correctly answer the } \\
\text { reasoning questions put forth during the lecture }\end{array}$ & $\begin{array}{c}3.79 \pm 0.85 \\
4(1)\end{array}$ & $\begin{array}{c}3.77 \pm 0.80 \\
4(1)\end{array}$ & 0.808 \\
\hline 9. & $\begin{array}{l}\text { The reasoning questions improved my academic } \\
\text { performance in histology }\end{array}$ & $\begin{array}{c}4.21 \pm 0.72 \\
4(1)\end{array}$ & $\begin{array}{c}4.26 \pm 0.76 \\
4(1)\end{array}$ & 0.639 \\
\hline 10. & $\begin{array}{l}\text { I would like to have similar methods of teaching in future } \\
\text { classes }\end{array}$ & $\begin{array}{c}4.31 \pm 0.58 \\
4(1)\end{array}$ & $\begin{array}{c}4.38 \pm 0.70 \\
4(1)\end{array}$ & 0.362 \\
\hline
\end{tabular}

aSI. No. - serial number; bSD - standard deviation; * - significant differences 


\begin{tabular}{|c|c|c|c|c|}
\hline Sl. No.a & Statement in questionnaire & $\begin{array}{c}\text { Male } \\
\text { Mean } \pm \text { SDb } \\
\text { Median } \\
\text { (Interquartile } \\
\text { range) }\end{array}$ & $\begin{array}{c}\text { Female } \\
\text { Mean } \pm \text { SDb } \\
\text { Median } \\
\text { (Interquartile } \\
\text { range) }\end{array}$ & $\begin{array}{c}\text { P value } \\
\text { (Mann- } \\
\text { Whitney U } \\
\text { test) }\end{array}$ \\
\hline 1. & $\begin{array}{l}\text { The reasoning-based questions asked in the lectures were } \\
\text { interesting }\end{array}$ & $\begin{array}{l}4.48 \pm 0.61 \\
5(1)\end{array}$ & $\begin{array}{l}4.43 \pm 0.72 \\
5(1)\end{array}$ & 0.920 \\
\hline 2. & $\begin{array}{l}\text { I understood what the lecturer was trying to ask through his } \\
\text { questions }\end{array}$ & $\begin{array}{l}4.35 \pm 0.56 \\
\quad 4(1)\end{array}$ & $\begin{array}{l}3.94 \pm 0.70 \\
\quad 4(0.25)\end{array}$ & $0.001^{*}$ \\
\hline 3. & $\begin{array}{l}\text { The reasoning questions enabled better understanding of } \\
\text { histology than lectures with fact-based questions }\end{array}$ & $\begin{array}{l}4.31 \pm 0.70 \\
\quad 4(1)\end{array}$ & $\begin{array}{l}4.12 \pm 0.83 \\
\quad 4(1)\end{array}$ & 0.250 \\
\hline 4. & $\begin{array}{l}\text { The time given for discussing the reasoning questions was } \\
\text { adequate }\end{array}$ & $\begin{array}{l}3.54 \pm 0.85 \\
\quad 4(1)\end{array}$ & $\begin{array}{l}3.82 \pm 0.78 \\
\quad 4(1)\end{array}$ & 0.093 \\
\hline 5. & $\begin{array}{l}\text { The reasoning questions motivated me to take part in } \\
\text { discussions during the lecture }\end{array}$ & $\begin{array}{l}4.38 \pm 0.69 \\
4.5(1)\end{array}$ & $\begin{array}{l}4.32 \pm 0.72 \\
\quad 4(1)\end{array}$ & 0.670 \\
\hline 6. & $\begin{array}{l}\text { The reasoning questions stimulated me to think for logical } \\
\text { responses }\end{array}$ & $\begin{array}{l}4.04 \pm 0.93 \\
\quad 4(1)\end{array}$ & $\begin{array}{l}4.20 \pm 0.78 \\
\quad 4(1)\end{array}$ & 0.401 \\
\hline 7. & The clues given during the questioning session were useful & $\begin{array}{l}3.61 \pm 0.84 \\
4(1)\end{array}$ & $\begin{array}{l}3.97 \pm 0.84 \\
\quad 4(2)\end{array}$ & $0.017^{*}$ \\
\hline 8. & $\begin{array}{l}\text { At the end of the lecture, I could correctly answer the reasoning } \\
\text { questions put forth during the lecture }\end{array}$ & $\begin{array}{l}4.08 \pm 0.79 \\
\quad 4(1)\end{array}$ & $\begin{array}{l}3.73 \pm 0.80 \\
\quad 4(1)\end{array}$ & $0.013^{*}$ \\
\hline 9. & $\begin{array}{l}\text { The reasoning questions improved my academic performance in } \\
\text { histology }\end{array}$ & $\begin{array}{l}4.11 \pm 0.78 \\
\quad 4(1)\end{array}$ & $\begin{array}{l}4.24 \pm 0.84 \\
\quad 4(1)\end{array}$ & 0.251 \\
\hline 10. & I would like to have similar methods of teaching in future classes & $\begin{array}{l}4.56 \pm 0.54 \\
5(1)\end{array}$ & $\begin{array}{l}4.44 \pm 0.64 \\
5(1)\end{array}$ & 0.415 \\
\hline
\end{tabular}

asI. No. - serial number; bSD - standard deviation; * - significant differences

design of histology lecture classes and considerable time devoted to them during the sessions to enhance learner engagement. Another common pitfall is the over-utilization of questions that require only factual recall to answer them. ${ }^{9,10}$ This is likely to be because of a perceived lack of value of higher-order questions among teachers and technical difficulties in framing such questions. ${ }^{10}$ These challenges were overcome in the current study by carefully framing questions and validating them prior to their utilization in lectures. It has been suggested that deep questioning in a collaborative setting followed by periods of reflection can facilitate learning. ${ }^{11}$ The method of questioning followed in this study incorporated these elements.

Previous studies have looked at learning outcomes after embedding multiple choice questions in lectures. ${ }^{8,16-19}$ In a study conducted among occupational therapy students, embedding multiple choice question during online lectures improved scores on an examination where transfer of learning was assessed. ${ }^{16}$ This was attributed to the testing effect, where students performed better when tested on the content rather than when they were exposed to the content that was already covered in the class. ${ }^{16}$ Similar results were noted among psychology students who performed better on retention and transfer tests when multiple choice questions were incorporated into lectures as compared to those in whom this material was presented in the form of statements. ${ }^{8}$ An intervention using audience response systems showed significantly greater short and long-term knowledge gain among students exposed to questions during the lecture as compared to those who were not. Higher levels of engagement and enjoyment were also expressed by the group of students among whom questions were used during the lecture. ${ }^{17} \mathrm{An}$ additional study suggested that it is the incorporation of questions, rather than the use of audience response systems that caused improved learning outcomes..$^{18}$ Another study utilized a variable number of multiple-choice questions of both low and high cognitive level during lectures. Adding more questions during lectures did not improve learning outcomes. The perceptions of students about the use of questions during lectures was positive. ${ }^{19}$

In a study conducted among health science students taking an undergraduate course in human anatomy and physiology, a collaborative quiz approach that guided students to discuss their understanding with peers was introduced. This intervention was compared to a shortanswer quiz where the students were not expected 
to justify their answers nor discuss them with peers. Subsequently, learning outcomes were measured using scores in an examination using multiple-choice questions. Significantly higher scores on examination questions associated with collaborative quiz topics than those associated with short-answer quiz topics were noted. The improved learning outcome was attributed to the students' articulation of the scientific reasoning process during the group discussions that facilitated metacognitive processes..$^{20}$ In the present study, students were not only expected to answer the questions that were posed, but also discuss them with peers. Additionally, the teacher used these questions to scaffold learning during the class.

The current study has demonstrated that both structure and function-based reasoning questions were able to promote student engagement during histology lectures. Learning in classes involves the processes of selection, organization and integration. ${ }^{8}$ The student needs to select the appropriate information during a teaching and learning session, organize the information and integrate it with pre-existing knowledge. When used effectively, questioning can enhance all these three processes and thereby facilitate learning. The anticipation of a question increases the attention of a student and thus improves the process of selection. Once the question is posed, the student will need to organize information and integrate it with prior learning to answer it. Finally, feedback provided after answering the question, triggers a process of self-assessment and aids the filling of identified learning gaps. ${ }^{8}$ The higher rating of the function-based questions could have been due to the immediate emotional response generated by the learner towards a relatable realworld scenario. In a previous study, gender differences have been noted in verbal and visuospatial working memory performance. ${ }^{21}$ Language processing among children too seems to show gender differences. ${ }^{22}$ The significant gender differences on scores in some items of the questionnaire could reflect these factors. The responses to the open-ended questions also seem to be in alignment with the scores on the questionnaire. The concern of some students about the inadequate coverage of the topic due to the lack of time points to the expectation of students from lectures for content delivery.

This study has some limitations. The learning outcomes of the questioning strategies were not measured. The current study design would have limited such an approach due to the many confounding factors that could have influenced the outcomes. Logistic considerations precluded the utilization a randomized control study design which would have been the ideal one. Despite these limitations, this study is likely to contribute to understanding how higher-level questions could facilitate student engagement during lectures. Medical educators could potentially utilize real-world scenarios as used in the current study when there is a paucity of clinical scenarios matching the course content. The metacognitive abilities of students exposed to such pedagogical approaches are likely to be enhanced, thus contributing to deep learning and improved learning transfer. Further research could focus on the change in learning outcomes associated with the reasoning approach described in the present study.

\section{Acknowledgement}

The authors would like to acknowledge the medical education unit of Sri Ramachandra medical College, Chennai for their support in designing the research project as part of advance course in medical education (ACME).

\section{References}

1. García M, Victory N, Navarro-Sempere A, et al. Students' Views on Difficulties in Learning Histology. Anat Sci Educ 2019;12(5):541-549.

2.Higazi TB. Use of interactive live digital imaging to enhance histology learning in introductory level anatomy and physiology classes. Anat Sci Educ 2011;4(2):78-83.

3. Kotze SH, Mole CG. Making large class basic histology lectures more interactive: The use of draw-along mapping techniques and associated educational activities. Anat Sci Educ 2015;8(5):463-470.

4. Balemans MC, Kooloos JG, Donders AR, et al. Actual drawing of histological images improves knowledge retention. Anat Sci Educ 2016;9(1):60-70.

5. McBride JM, Prayson RA. Development of a synergistic case-based microanatomy curriculum. Anat Sci Educ 2008;1(3):102-105.

6.Payne L. Student engagement: three models for its investigation. Journal of Further and Higher Education 2017;1-17.

7. Christenson SL, Reschly AL, Wylie C. Handbook of Research on Student Engagement. 1st Ed. New York: Springer; 2012.

8. Campbell J, Mayer RE. Questioning as an instructional method: Does it affect learning from lectures? Applied Cognitive Psychology 2009;23(6):747-759.
9. Sachdeva AK. Use of effective questioning to enhance the cognitive abilities of students. J Cancer Educ 1996;11(1):17-24.

10. Tofade T, Elsner J, Haines ST. Best practice strategies for effective use of questions as a teaching tool. Am J Pharm Educ 2013;77(7):155. 11. Kost A, Chen FM. Socrates was not a pimp: changing the paradigm of questioning in medical education. Acad Med 2015;90(1):20-24.

12. Long M, Blankenburg R, Butani L. Questioning as a teaching tool. Pediatrics 2015;135(3):406-408.

13. Black VH, Smith PR. Increasing active student participation in histology. Anat Rec B New Anat 2004;278(1):14-17.

14. Schönrock-Adema J, Bouwkamp-Timmer T, van Hell EA, et al. Key elements in assessing the educational environment: where is the theory?. Adv Health Sci Educ Theory Pract 2012;17(5):727-742.

15. Cho YH, Lee SY, Jeong DW, et al. Analysis of questioning technique during classes in medical education. BMC Med Educ 2012;12:39.

16. Griswold LA, Overson CE, Benassi VA. Embedding Questions During Online Lecture Capture to Promote Learning and Transfer of Knowledge. Am J Occup Ther 2017;71(3):7103230010p1-7103230010p7.

17. Mains TE, Cofrancesco J Jr, Milner SM, et al. Do questions help? The impact of audience response systems on medical student learning: 
a randomised controlled trial. Postgrad Med J 2015;91(1077):361-367. 18. Anthis, K. Is it the clicker, or is it the question? Untangling the effects of student response system use. Teaching of Psychology 2011;38(3):189-193.

19. Hessheimer HM, Rogo EJ, Howlett B. Use of questioning during lectures in a dental hygiene didactic course. J Dent Educ 2011;75(8):1073-1083.

20. Krontiris-Litowitz J. Articulating scientific reasoning improves student learning in an undergraduate anatomy and physiology course. CBE Life Sci Educ 2009;8(4):309-315.

21. Zilles $D$, Lewandowski $M$, Vieker $\mathrm{H}$, et al. Gender Differences in Verbal and Visuospatial Working Memory Performance and Networks. Neuropsychobiology 2016;73(1):52-63.

22. Burman DD, Bitan T, Booth JR. Sex differences in neural processing of language among children. Neuropsychologia 2008;46(5):1349-1362.

\section{Mini Curriculum and Author's Contribution}

1. Suresh Narayanan - MD. Contribution: Conceptualization of the research design, data collection, data analysis, drafting of the manuscript, critical review and final approval. (ORCID: 0000-0003-2558-9811)

2. Nachiket Shankar - MD. Contribution: Conceptualization of the research design, data analysis, drafting of the manuscript, critical review and final approval. (ORCID: 0000-0002-0520-0680)

3. Vimala Ananthy - MD. Contribution: Conceptualization of the research design, drafting of the manuscript, critical review and final approval. (ORCID: 0000-0002-5124-9821)

Received: Abril 6, 2021

Accepted: May 6, 2021
Corresponding author

Suresh Narayanan

E-mail: nsuresh3888@gmail.com 